\title{
The Outlook of Building Information Modeling for Sustainable Development
}

Heap-Yih Chong ${ }^{1}$ and Xiangyu Wang ${ }^{2,3}$

${ }^{1}$ School of Built Environment, WA 6845, Australia. Corresponding email: heap-yih.chong@curtin.edu.au, Tel: +6189266 3766, Fax: +61892662711

${ }^{2}$ School of Built Environment, WA 6845, Australia.

${ }^{3}$ Department of Housing and Interior Design, Kyung Hee University, Seoul, Korea.

\begin{abstract}
:
As human needs evolve, information technologies and natural environments require a wider perspective of sustainable development, especially when examining the built environment that impacts the central of socialecological systems. The objectives of the paper are (a) to review the status and development of Building Information Modeling (BIM) in regards to the sustainable development in the built environment, and (b) to develop a future outlook framework that promotes BIM in sustainable development. Seven areas of sustainability were classified to analyze forty-four BIM guidelines and standards. This review examines the use of BIM in sustainable development, focusing primarily on certain areas of sustainability, such as project development, design and construction. The developed framework describes the need for collaboration with the multiple disciplines for the future adoption and use of BIM for the sustainable development. It also considers the integration between "BIM and green assessment criteria"; and "BIM and renewable energy" to address the shortcomings of the standards and guidelines.
\end{abstract}

Keywords: Review, BIM, Sustainable Development, Technology, Outlook, Framework, Built Environment

\section{Introduction}

The concept of sustainable development is rapidly evolving to embrace the ongoing relationship among social, economy and natural systems. Innovations in science and technology play a critical role to supporting a transition toward the sustainable development, especially for cleaner productions and operational processes (Kranvanja et al. 2015). Built environment has impacted the center of social-ecological systems. It refers to any human-made structures or surroundings for supporting the society and economy. When implementing sustainable practices in the built environment, it is important to engage construction stakeholders (Petri et al., 2015). Building Information Modeling (BIM) is one of a sustainable technology that can be used to create and utilized digital information to monitor a project throughout its lifecycle. BIM technology has been receiving a tremendous amount of attention from the academia and industry, and offers the potential to transform the conventional project delivery approach (Eastman et al., 2011). BIM is a coordinated, and its consistent data store offers a collaborative working platform for all project stakeholders (Rogers et al., 2015). This innovative approach is able to improve the unproductive and fragmented practice that is currently used in the built environment. Using BIM technologies allow all parties to have the same goal and knowledge into the project 
in advance from different dimensional models, namely, three dimensional model (3D), time-related model (4D), cost-related model (5D) and facility management-related model (6D), which are largely contributed by the BIM's virtual and geometry information (Lopez et al., 2015). The applications and uses of BIM allow for sustainable approaches to improve performance (Chong et al., 2014) throughout different stages of the project lifecycle (Wong and Fan, 2013,).

Previous studies mainly focused on the technological aspects of BIM that developed new and improved BIM applications and uses for the architecture, engineering and construction (AEC) aspects (Wang and Chong, 2015) in buildings or infrastructures (Shou et al., 2015). Although certain sustainability concepts and improvements have been mentioned part and parcel from the previous studies, no prior BIM related research or review has emphasized on the sustainable development for the entire built environment from a holistic perspective. Therefore, the objectives of the paper are (a) to review the status and development of BIM for the sustainable development in the built environment, and (b) to develop a future outlook framework to promote BIM's use in sustainable development. The review approach adopted a neutral and established perspective on the development of BIM, which all BIM guidelines and standards from different countries were reviewed. This approach was selected so as to provide a clear understanding on the actual practice of BIM in the built environment. Subsequently, the future outlook framework has been developed to address the gaps from the review, and also to promote the integrative approach for sustainability practices.

The findings will strengthen the existing systems and policies, and provide important insights into promoting a sustainable built environment through the use of BIM technology. The review approach and analysis method are generalizable for other sustainability technologies in different sectors and industries.

\section{Review approach}

BIM is an evolving technology. While it has been well-developed and received, it has yet to have comprehensive policies and regulations to popularize the technology (Bossink, 2015); especially from the sustainable development perspective. Therefore, the neutral review approach was adopted, where all the standards and guidelines in relation of BIM were reviewed to determine the actual implementation of BIM in contributing into the sustainable development. It was a different approach from reviewing journal or conference articles because the sources would cover a wider view on BIM status and development across different disciplines and sectors in the built environment. The standards and guidelines were selected based on the popularity and references cited in academic publications and industrial magazines/reports. Most of them were derived from developed countries that have been using BIM technologies for several decades (Eastman et al., 2011). These sources would be a good and reliable reference to examine for the sustainable development in the built environment.

Subsequently, there is a need to organize sustainability areas according to the built environment working culture. The latest Royal Institute of British Architects (RIBA)'s Plan of Work 2013 was referred for the 
organization of the sustainability areas. It is because the Plan includes many new activities (including BIM) into the project lifecycle (Bordass and Leaman, 2014). Consequently, the related sustainability areas were formulated and modified based on the idea derived from the stages of work in the project lifecycle. Seven (7) sustainability areas were classified according to a number of aspects throughout the project lifecycle, namely,

- Development - this area describes to planning and development of the project including the required project delivery approaches or procurement systems. BIM can contribute effective and efficient processes in the project planning and development (Gibbs et al., 2015). This process reduces reworks and unnecessary wastes from re-planning and re-development.

- Design - this area describes the design of the project by all design teams, namely, architects and engineers. BIM will improve design and coordination among the design teams for a more practical and constructability of the project (Singh et al., 2011).

- Construction - this area describes the construction process of the project. BIM can prepare an early visualization or forecast on time, cost and quality in a 3D environment (Wang et al., 2014). It will avoid errors in construction processes and improve the constructability or methods used in the project (Wang et al., 2016).

- Materials - this area describes the use of the materials and methods for the project. BIM can encourage and test new materials from the virtual 3D environment (Kim et al., 2015). It will improve the project life-span and performance.

- Energy consumption - this area describes the related tools and techniques in operating the project. BIM can perform energy simulation of heating, ventilation, air conditioning and lighting as required in the project (Ahn, et al., 2014). It will reduce the energy and power use in a project.

- Maintenance - this area describes the maintenance of a project. BIM can provide a centralized and integrated facility management from the virtual environment (Chong et al., 2014). It can forecast and schedule the maintenance needs efficiently. This would help in providing a transparent platform for facilitating informed-decision making in facility management (Reza et al., 2014).

- Demolition - this area describes the required refurbishment or demolition at the end of the project lifespan. BIM can simulate every element in the project with the required specification and dimensions (Yun, et al., 2014). It will support in selecting the right method for demolition or refurbishment.

\section{Findings}

Forty-four BIM standards and guidelines were collected from nine countries to review the status and development of BIM for the sustainable development. They were analyzed as per the categorized sustainability areas as shown in Table 1.

Most of the standards and guidelines were derived from United States of America, followed by Australia and United Kingdom. They were developed by universities, government sectors and non-governmental 
organizations for the industry use. The most cited and popular BIM standard was National BIM Standard, which was published by National Institute of Building Science and buildingSMART alliance in United States of America.

<Insert Table 1 here>

The qualitative data were converted to quantitative data based on the number of appearance in the review as shown in Table 2. A total of one hundred forty-two sustainability areas were covered and repeated from the standards and guidelines. The design area had the largest number of appearances, and recorded forty two of them. It was followed by the areas of development and construction, which were thirty nine and thirty-one. The areas of maintenance, materials and energy consumptions received only sixteen, eight and six respectively. Surprisingly, none of the standards and guidelines mentioned about the sustainability area of demolition.

<Insert Table 2 here>

The results show an interesting finding on the current practice of BIM in the built environment, which was focused on the development and design aspects of the guidelines and standards. It has had a significant different compared to the critical review on articles in relation to BIM that was carried out recently by Volk et al. (2014), which most of the articles were identified and focused on energy analysis, lifecycle assessment, sustainability, and retrofit/refurbishment. As the guidelines and standards have been developed for the current need and practice in the industry, this comparison indicates that the current practice for sustainability has not covered for the research findings in those areas as published by the journal articles. This is probably due to the lack of awareness or verification on their potential uses in the industry. This different perspective will provide a good point-of-reference when developing the future outlook framework.

From a holistic perspective, most of the standards and guidelines were focused on the areas of development, design, construction and maintenance. This is important as these areas serve as the foundation in the preliminary stage for effective adoption and use of BIM technology in the project. These standards and guidelines will facilitate the practice and coordination of BIM among the stakeholders and designers in the collaborative platform. These sustainable practices will contribute towards improved performance and avoidance of unnecessary waste throughout these processes, as stakeholders can make informed decisions by accessing BIM model data. As a result, it could prevent reworks and errors occurred and indirectly contribute to the sustainable development in the built environment.

Apart from that, other sustainability areas would have a greater and direct impact and influence towards the sustainable development, namely, energy consumption, materials and demolition. However, in the current 
BIM standards and guidelines, there are only limited coverage in these areas. The industry should use certain BIM applications and work with the green materials and efficient energy consumptions within buildings or infrastructures to better protect the environment and save on energy use (Yadollahi et al., 2014). BIM can also contribute towards the demolition area as the practice of demolition is rather complicated, and a virtual simulation would help in planning and decision making before the actual demolition. It would provide a fast and accurate waste estimation for demolition projects, and subsequently it could also optimise energy efficiency of the demolition process (Cheng and Ma, 2012). These areas need to be considered in the development of the future outlook framework.

\section{Discussions}

BIM has contributed towards certain areas of the sustainable development in the built environment. However, a lot of work need to done to achieve effective outcomes for the categorized sustainability areas. For instance, the green assessments can be referred to strengthen the findings of the review. Some of the recognized and popular indexes are Leadership in Energy and Environmental Design (U.S. Green Building Council, 2016), Building Research Establishment Environmental Assessment Methodology (BREEAM, 2016), Green Star (Green Building Council Australia, 2016) and Green Building Index (GBI Malaysia, 2016). Yet, the current practice heavily focuses on construction aspects for green buildings (Chen and Hong, 2015). New guidelines and practical tools are needed to support and define the requirements and steps involved for BIM to achieve and fulfil the certification assessment. Particularly, the indexes should be integrated with the sustainability areas of materials, energy consumption and demolition from the BIM perspective. This approach is feasible as the green assessment criteria are rather generic and fit the required sustainable improvements in the built environment. These sustainability areas can be achieved through the simulations conducted using specialized BIM software during the design stage of the project. Doing this will allow for the production of energy-efficient, healthier and more environmentally conscious buildings.

BIM should also incorporate more sustainability functions when dealing with climate changes and greenhouse effects. BIM can simulate the energy and water usage within an asset. BIM allows its user to design the optimum consumption of the energy and water from different sources of energy or watering systems. For instance, the clean or renewable energy should be considered in the asset, which it will create a tremendous sustainability impact to the built environment through its policy (Chong and Lam, 2013) or technology (Sakmani et al., 2013). The integration of the clean or renewable energy with BIM is a new concept. It will create various opportunities to both industry and academia. From a conceptual point of view, it can optimize the energy use and carbon emissions from buildings or infrastructures, and subsequently it can extend to a community, a town or even a city. It will not only save the energy use, but the additional energy can be reserved or even generated for other use in the area (for example, solar panels). This will contribute significantly to the natural environment. 
Overall, the paper highlights that the current standards and guidelines have contributed on certain sustainability areas in the built environment. The needs for the integrations between (a) BIM and green assessment criteria, and (b) BIM and renewable energy are the important implications of the review. The integrations will address the shortcomings of coverage on the sustainability areas.

\section{Future Outlook Framework}

The integrations between (a) BIM and green assessment criteria, and (b) BIM and renewable energy should collaborate with multiple disciplines as to support the effective adoption and use of BIM for the sustainable development. It is because the norm practice of sustainability technologies is to primarily focus on an individual approach within the single discipline, which will create barriers to the market entry (Hoppmann et al., 2013). Consequently, some recent studies have begun to look into the integrative approach in addressing the sustainability issues through their policies (Teschner et al. 2012) or deployment strategies (Erzurumlu and Erzurumlu 2013). As a result, the framework development should consider the integrative approach from various disciplines or sectors. Yet, the multidisciplinary integrative approach is very challenging as it requires a high level of integration and knowledge from various disciplines.

Therefore, an attempt to integrate different disciplines is initiated in this paper. Firstly, it needs to identify all related disciplines. The identification of the disciplines is rather a subjective process, but two arbitrary rules have been adopted in the process namely, (a) the disciplines need to uphold current and future BIM development that will integrate with other advanced technologies to contribute towards sustainable development and overall project performance (Wang and Chong, 2015), and (b) the disciplines should be based on an embracing holism philosophy to accommodate the increased complex characteristics and policies in the planning, design, construction and operation of the built environment (Lizarralde et al., 2014). After the detailed consideration, six generic disciplines have been identified such as, law, management, information communication and technology (ICT), engineering, energy, and health science.

Next, the identified disciplines need to connect with the seven sustainability areas in the built environment as shown in Table 3. This is to promote a collaborative working environment of BIM that can support the integration and enhance working relationships among the disciplines. Some practical examples have been proposed to explain clearly the potential areas of the integration for improving sustainable development in the built environment. The law and management disciplines are perceived as the fundamental processes for all the sustainability areas.

<Insert Table 3 here>

The development of the future outlook framework is focused on promoting BIM as a way of addressing sustainable development in the built environment. The development process needs to consider the findings and gaps as identified from the review, and also to correlate with the multiple disciplines as highlighted. As a 
result, the framework (Figure 1) was developed with the intention of describing and accommodating the concerns above into a simplified manner. It explains the need for developing more standards and guidelines for the sustainability areas of materials, energy and demolition. Meanwhile, new functions of BIM should be explored in future practices so as to incorporate the built environment with green assessment criteria and renewable energy. All these processes should work under a collaborative platform with the related disciplines to tackle the sustainable development. It can start from a single asset either in building or infrastructure, and extend it to a bigger community area.

$<$ Insert Figure 1 here>

In summary, this paper renders three main contributions. First, the review has uncovered certain sustainability areas that require serious attention and development by the universities, governments or nongovernment organizations. Second, the paper has proposed two new integrations for BIM with green assessment criteria and renewable energy. Lastly, the framework has highlighted the integrative approach with different disciplines in promoting for sustainability practices for BIM in the built environment.

\section{Conclusions}

This study has provided a review on the status and development of BIM for sustainable development in the built environment based on forty-four BIM guidelines and standards. The review has classified the guidelines and standards into seven sustainability areas. The results show that the sustainability areas of development, design and construction are the main focus areas in BIM. This paper has developed a future outlook framework in promoting BIM for the sustainable development. The framework has considered the gaps from the review on the sustainability areas of materials, energy and demolition and has also incorporated the integrative approach for sustainability practices for BIM with green assessment criteria and renewable energy under a multidisciplinary platform.

Certain limitations need to be considered in the review. The review sources have not adopted other BIM standards or guidelines that are published by vendors as to preserve the neutral position for the data analysis. Some BIM standards or guidelines may also not be included in the review, especially from the developing countries. The limitations serve as reminders that this review is not definitive as some useful information may change the results of the review. Nevertheless, the review has successfully achieved the objectives and rendered insightful references in promoting the sustainability practices for BIM in the built environment. Certain areas of the review approach and the framework can be generalized and referred by other sustainability technologies in different sectors. 


\section{References}

AEC UK (2011) BIM Standard for AEC industry in UK, AEC (UK) committee: London, UK.

AEC UK (2012) AEC (UK )BIM Protocol: London, UK.

Ahn, K. U., Kim, Y. J., Park, C. S., Kim, I., \& Lee, K. (2014). BIM interface for full vs. semi-automated building energy simulation. Energy and Buildings, 68, 671-678.

AFCEECIM (2012) “ATTACHMENT F” - BIM Requirement, United States Air Force Center for Engineering and the Environment Capital Investment Management USA, San Antonio-Lackland, USA.

AGC (2009) The Contractor's Guide to BIM, Associated General Contractors of America: Virgina, USA.

AIA (2008) E202-2008 BIM Protocol, American Institute of Architects: Washington, USA.

AMCA (2011) BIM-MEPAUS Practice, Mechanical Contractors' Association: Victoria, Australia.

AOES (2012) BIM Guidelines \& Standards for Architects, Engineers, and Contractors, Indiana University Architect's Office and Engineering Services: Indiana, USA.

BCA (2012) Singapore BIM Guide, Building and Construction Authority: Singapore.

Bordass, B., \& Leaman, A. (2014). BUILDING PERFORMANCE EVALUATION IN THE UK. Architecture Beyond Criticism: Expert Judgment and Performance Evaluation, 160.

Bossink, B. A. (2015). Demonstration projects for diffusion of clean technological innovation: a review. Clean Technologies and Environmental Policy, 17, 1409-1427.

BSI (2007). BS 1192:2007 Collaborative production of architectural, engineering and construction information. Code of practice. BSI: London, UK.

BSI (2010). BIP 2207 Building information management. A standard framework and guide to BS 1192.BSI: London, UK.

BuildingSMART Finland (2012a) Yleiset tietomallivaatimukset 2012, buildingSMART Finland: Helsinki, Finland.

BuildingSMART Finland (2012b). Common BIM Requirements 2012. buildingSMART Finland: Helsinki, Finland.

BREEAM (2016, March 1). BREEAM at a glance. Retrieved from http://www.breeam.com/why-breeam

Chen, W., \& Hong, X. (2015). Design of effective subsidy policy to develop green buildings: from the perspective of policy benefit. Clean Technologies and Environmental Policy, 17(4), 1029-1038.

Cheng, J., \& Ma, L. (2012). A BIM-based system for demolition and renovation waste quantification and planning. In Proceedings of the 14th International Conference on computing in Civil and Building Engineering (ICCCBE 2012), Moskow.

Chong H.Y., Lam W.H. (2013). Ocean renewable energy in Malaysia: The potential of the Straits of Malacca. Renewable \& Sustainable Energy Reviews, 23, 169-178.

Chong, H. Y., Wang, J., Shou, W., Wang, X., \& Guo, J. (2014). Improving Quality and Performance of Facility Management Using Building Information Modelling. In Cooperative Design, Visualization, and Engineering (pp. 44-50). Springer International Publishing.

CoD (2011) BIM GUIDE, College of the Desert: California, USA.

CIC (2013) Best Practice Guide for Professional Indemnity Insurance when using BIM and, Outline Scope of Services, Construction Industry Council UK: London, UK 
CIMS (2011) BIM Development Criteria and Standards for Design \& Construction Projects Capital Improvements Management Services San Antonio: San Antonio, USA.

CORENET (2011) CORENET e-submission System Construction and Real Estate NETwork: Singapore.

CPEC (2011) MIT CAD \& BIM Guidelines, MIT Campus Planning, Engineering, and Construction: Boston, USA.

CPO (2012) Attachment G - University of Washington CAD and BIM Standards, University of Washington Capital Projects Office: Seattle, USA.

CRC (2009) National Guidelines and Case Studies for Digital Modelling, Cooperative Research Centre for Construction Innovation: Brisbane, Australia.

DDC (2012) BIM Guidelines, Department of Design\&Construction: New York, USA.

DOA/DSF (2009) BIM Guidelines \& Standards for ARCHITECTS and ENGINEERS Department of Administration, Division of State Facilities: Wisconsin, USA.

Eastman, C., Teicholz, P., Sacks, R., \& Liston, K. (2011). BIM handbook: A guide to building information modeling for owners, managers, designers, engineers and contractors. John Wiley \& Sons, New York, USA.

Erzurumlu S.S., Erzurumlu Y.O. (2013). Development and deployment drivers of clean technology innovations. Journal of High Technology Management Research, 24,100-108.

FMS (2012) BIM Guidelines, University of Southern California Facilities Management Services: California, USA.

GBI Malaysia (2016, March 1). What and why green buildings? Retrieved from http://new.greenbuildingindex.org/whatandwhy

Gibbs, D. J., Emmitt, S., Lord, W., \& Ruikar, K. (2015). BIM and Construction Contracts: CPC 2013's approach. Proceedings of the ICE-Management, Procurement \& Law. In press.

Green Building Council Australia (2016, March 1). Green Star. Retrieved from https://www.gbca.org.au/greenstar/

GSA (2007) National 3D-4D BIM Program, United States General Services Administration: Washington, USA. GSA (2012) National 3D-4D BIM Program, United States General Services Administration: Washington, USA GSFIC (2013) BIM Guide, Georgia State Financing and Investment Commission: Georgia, USA.

GTFM (2011) Georgia Tech BIM Requirements \& Guidelines for Architects, Engineers and Contractors, Georgia Tech Facilities Management: Georgia, USA.

HKIBIM (2011) BIM Project Specification, The Hong Kong Institute of Building Information Modeling: Hong Kong.

Hoppmann J., Peters M., Schneider M., Hoffmann V.H. (2013). The two faces of market support—How deployment policies affect technological exploration and exploitation in the solar photovoltaic industry. Research Policy, 42, 989-1003.

Kim, M. K., Cheng, J. C., Sohn, H., \& Chang, C. C. (2015). A framework for dimensional and surface quality assessment of precast concrete elements using BIM and $3 \mathrm{D}$ laser scanning. Automation in Construction, 49, 225-238.

Kravanja, Z., Varbanov, P. S., \& Klemeš, J. J. (2015). Recent advances in green energy and product productions, environmentally friendly, healthier and safer technologies and processes, CO2 capturing, 
storage and recycling, and sustainability assessment in decision-making. Clean Technologies and Environmental Policy, 17(5), 1119-1126.

LACCD (2011) BIM Standard, Los Angeles Community College District: California, USA.

Lizarralde, G., Chmutina, K., Bosher, L. S., \& Dainty, A. R. (2014). Tensions and complexities in creating a sustainable and resilient built environment: achieving a turquoise agenda in the UK. (C) Global Risk Forum GRF Davos.

Lopez, R., Chong, H. Y., Wang, X., \& Graham, J. (2015). Technical Review: Analysis and Appraisal of FourDimensional Building Information Modeling Usability in Construction and Engineering Projects. Journal of Construction Engineering and Management, 06015005.

MIKR (2012) Rgd BIM Standard, Rijksgebouwendienst (Ministry of the Interior and Kingdom Relations): The Netherlands.

NAEC (2007) Det Digitale Byggeri (Digital Construction), Erhvervsstyrelsen (National Agency for Enterprise and Construction): Copenhagen, Denmark.

NATSPEC (2011) NATSPEC National BIM Guide, Construction Information Systems Limited ABN 20117 574 606: Sydney, Australia.

NHBA (2011) BoligBIM (BIM Manual), Boligprodusentene (Norwegian Home Builders Association): Oslo, Norway.

NIBS (2012) National BIM Standard National Institute of Building Science: Washington, USA.

NYSCA (2012) BIM Guidelines and Standards for Architects and Engineers, New York City School Construction Authority: New York, USA.

OFCC (2012) BIM Protocol, State of Ohio Facilities Construction Commission: Ohio, USA.

PANY\&NJED (2012) EAD (E/A Design Division) BIM Standard Manual, The Port Authority of NY \& NJ Engineering Department: New York, USA.

Petri, I., Rezgui, Y., Beach, T., Li, H., Arnesano, M., \& Revel, G. M. (2015). A semantic service-oriented platform for energy efficient buildings. Clean Technologies and Environmental Policy, 17(3), 721-734.

PSU (2012) BIM Planning Guide for Facility Owners, The Pennsylvania State University: Pennsylvania, USA.

Reza, B., Sadiq, R., \& Hewage, K. (2014). Emergy-based life cycle assessment (Em-LCA) for sustainability appraisal of infrastructure systems: a case study on paved roads. Clean Technologies and Environmental Policy, 16(2), 251-266.

Rogers, J., Chong, H. Y., \& Preece, C. (2015). Adoption of Building Information Modelling technology (BIM) Perspectives from Malaysian engineering consulting services firms. Engineering, Construction and Architectural Management, 22(4), 424-445.

Sakmani, A. S., Lam, W. H., Hashim, R., \& Chong, H. Y. (2013). Site selection for tidal turbine installation in the Strait of Malacca. Renewable and Sustainable Energy Reviews, 21, 590-602.

SBEnrc (2015). National BIM Guidelines and Case Studies for Infrastructure. SBEnrc: Perth, Australia.

SDCCD (2012) BIM Standards for Architects, Engineers \& Contractors, San Diego Community College District: California, USA.

SEC (2013) First Steps to BIM Competence: A Guide for Specialist Contractors, Specialist Engineering Contractors' Group and BIM Academy at the University of Northumbria: Northumbria, UK. 
Shou, W., Wang, J., Wang, X., \& Chong, H. Y. (2015). A Comparative Review of Building Information Modelling Implementation in Building and Infrastructure Industries. Archives of Computational Methods in Engineering,22(2), 291-308.

Singh, V., Gu, N., \& Wang, X. (2011). A theoretical framework of a BIM-based multi-disciplinary collaboration platform. Automation in Construction, 20(2), 134-144.

Statsbygg (2012) Statsbygg BIM Manual, Statsbygg: Oslo, Norway.

Teschner N., McDonald A., Foxon T.J., Paavola J. (2012). Integrated transitions toward sustainability: The case of water and energy policies in Israel. Technological Forecasting \& Social Change, 79, 457-468.

TFC (2010) Professional Service Provider Guidelines and Standards, Texas Facilities Commission: Texas, USA.

USACE (2012) Roadmap for Life-Cycle BIM, United States Army Corps of Engineers USA.

U.S. Green Builidng (2016, March 1). Better buildings are our legacy. Retrieved from http://www.usgbc.org/leed

USVA (2010) BIM guide, Veterans Affairs: Washington, USA.

Volk, R., Stengel, J., \& Schultmann, F. (2014). Building Information Modeling (BIM) for existing buildingsLiterature review and future needs. Automation in Construction, 38, 109-127.

Wang, J., Wang, X., Shou, W., Chong, H. Y., \& Guo, J. (2016). Building information modeling-based integration of MEP layout designs and constructability. Automation in Construction, 61, 134-146.

Wang, X., \& Chong, H. Y. (2015). Setting New Trends of Integrated Building Information Modelling (BIM) for Construction Industry. Construction Innovation,15(1), 2-6.

Wang, X., Truijens, M., Hou, L., Wang, Y., \& Zhou, Y. (2014). Integrating Augmented Reality with Building Information Modeling: Onsite construction process controlling for liquefied natural gas industry. Automation in Construction, 40, 96-105

Wong, K.-d. \& Fan, Q. (2013). Building information modelling (BIM) for sustainable building design, Facilities, 31 (3/4), 138-157.

Yadollahi, M., Ansari, R., Abd Majid, M. Z., \& Yih, C. H. (2014). A multi-criteria analysis for bridge sustainability assessment: a case study of Penang Second Bridge, Malaysia. Structure and Infrastructure Engineering, (ahead-of-print), 1-17.

Yun, S. H., Jun, K. H., Son, C. B., \& Kim, S. C. (2014). Preliminary study for performance analysis of BIMbased building construction simulation system.KSCE Journal of Civil Engineering, 18(2), 531-540. 